\title{
BASED ON EMERGY ANALYTICAL METHODOLOGY TO EVALUATE ECOLOGICAL DEGREE OF URBAN ECOSYSTEM: A QUANTITATIVE ECOLOGICAL ASSESSMENT OF YANGZHOU CITY IN CHINA
}

\author{
JUNXUE ZHANG \& CHANGHAI PENG \\ School of Architecture, Southeast University, PR China
}

\begin{abstract}
As one of the most famous ancient capitals in China, Yangzhou city has more than two thousand years of history and holds a vital position in southern China. With the rapid development of the economy, the ecological environment has also deteriorated, so the ecological assessment of Yangzhou city becomes more and more important. As a typical ecological assessment method, emergy theory has lots of advantages, because it is a quantitative assessment method. The research scope of this paper involves renewable resources and a nonrenewable exchange in Yangzhou city. In this paper, some parameters of Yangzhou city are discussed to evaluate ecology through emergy indexes. Simultaneously, by analyzing the changes of GDP from 2012 to 2016, the economic development and ecological changes of Yangzhou City are compared and evaluated. The results of emergy analysis show that renewable resources almost have no change from 2012 to 2016 and non-renewable resources have rapid growth. With the development of Yangzhou city, Environmental loading ratio (ELR) increases quickly from 2012 to 2016. The urban ecological sustainability has no improvement. In addition to emergy analysis, the GDP analysis results demonstrate that Yangzhou's GDP and per capita GDP grows rapidly from 2012 to 2016. However, there is no satisfied effect for the structural adjustment that the government has executed. Although the product of secondary industry has decreased, the scale of the tertiary industry has not enhanced. In conclusion, the development in recent years has not achieved sustainable ecological development in Yangzhou city.
\end{abstract}

Keywords: urban ecology, emergy methodology, quantitative assessment, ecological indexes, Yangzhou city, structural adjustment.

\section{INTRODUCTION}

As one of the ancient cities in China, Yangzhou city has more than 2000 years of history. As the representative ancient capital of China, the sustainable development of Yangzhou city has a larger reference for cities in southern China.

With the rapid development of economic, the deterioration of the ecological environment also has been generated. During the development of Yangzhou city from 2012 to 2016, the government has tried to reduce the deterioration of the environment by adjusting the industrial structure.

Emergy theory, as an embodied energy, is different from traditional energy, has greater advantage for evaluating the ecological sustainability of city [1]. Some studies of using emergy method to evaluate citys have been performed in some regions and countries, including China [2], Italy [3], Taipei [4], Macao [5], Hong Kong [6].

In this study, through emergy method to analyze the indexes of Yangzhou city, the aim is to assess the level of ecological assessment and check the structural adjustment effect of government, so as to optimize and improve political strategy. 


\section{METHODOLOGY}

\subsection{Emergy method}

\subsubsection{Emergy method introduction}

Emergy analytical methodology was established by famous ecologist H. T. Odum of the United States [7].

Emergy's English spelling has a letter " $\mathrm{m}$ " and it is different from energy. The word of emergy, developed through long-term research and is an important scientific concept. Odum defines the emergy as the amount of available energy that is directly or indirectly put into use during the formation of a product or labor service.

In practical applications, the emergy of a unit energy is measured by solar energy. Any energy starts from solar energy, so solar energy is used as a standard to measure any kind of energy. Solar joule is the unit of emergy. Different non-comparable energy can be converted into the same standard (emergy) to be compared.

The transformity is the emergy of per unit of energy $(\mathrm{J})$ or substance $(\mathrm{g})$, so the unit of transformity is $\mathrm{sej} / \mathrm{j}$ or $\mathrm{sej} / \mathrm{g}$. The bigger transformity demonstrates higher hierarchy in the energy system.

\subsubsection{Emergy calculated boundary}

Fig. 1 is the emergy flow of Yangzhou city. It is a brief picture to demonstrate the holistic emergy flow in order to provide the calculation boundary. The specific calculated contents are shown in Tables 2 and 3.

\subsubsection{Emergy assessment indexes}

Some indexes of emergy method have been listed in Table 1 [8]-[11].

\subsection{GDP assessment method}

Another analysis method is the GDP assessment method. By comparing the change of GDP and emergy results from 2012 to 2016 in Yangzhou city, the development level of Yangzhou city has been assessed.

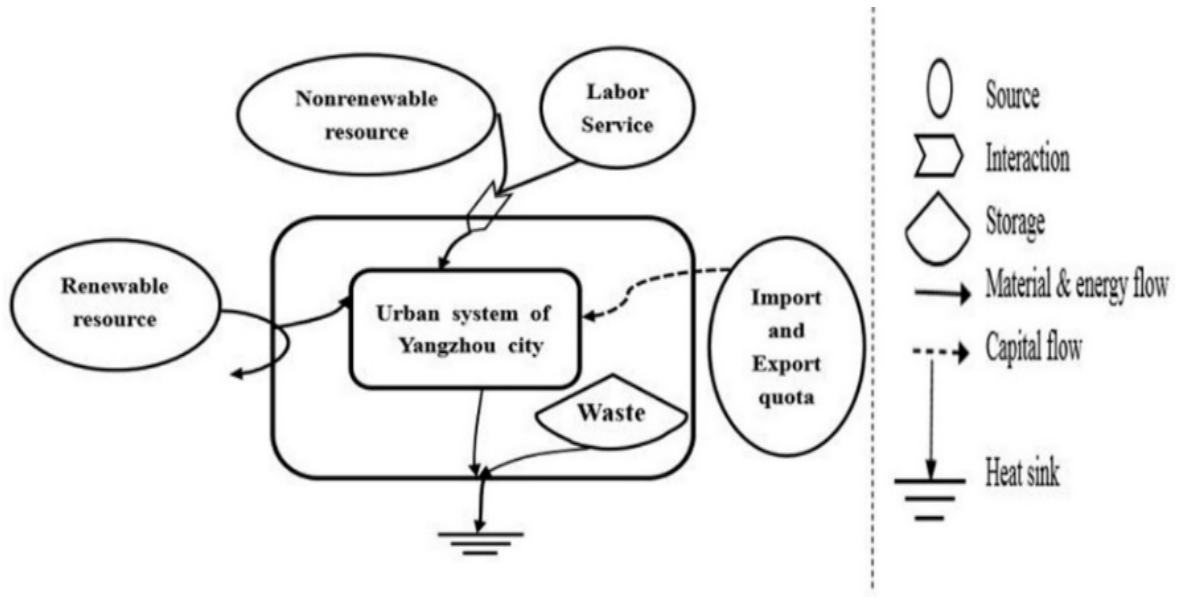

Figure 1: A system diagram of emergy evaluation of Yangzhou city. 
Table 1: The indexes of emergy evaluation.

\begin{tabular}{|l|l|l|}
\hline Indicator & Description & Unit \\
\hline $\mathrm{R}$ & Renewable resource parts & sej \\
\hline $\mathrm{N}$ & Non-renewable resource parts & sej \\
\hline $\mathrm{Y}$ & Total emergy= N + R & sej \\
\hline $\mathrm{F}$ & Import and export emergy & sej \\
\hline Ep & Emergy per population & sej/person \\
\hline Em & Emergy per capita & sej/money \\
\hline Ec & Emergy per area & sej/m $^{2}$ \\
\hline ELR & Emergy loading ratio: $(\mathrm{N}+\mathrm{F}) / \mathrm{R}$ & $\sim$ \\
\hline EYR & Emergy Yield ratio: Y/F & $\sim$ \\
\hline ESI & Emergy sustainable index: EYR/ELR & $\sim$ \\
\hline
\end{tabular}

\section{RESULTS AND DISCUSSION}

3.1 Emergy evaluation part

3.1.1 Renewable energy calculation of Yangzhou city

See Tables 2-5.

\subsubsection{Ecological assessment calculated table}

The raw data of Table 6 consists of renewable, non-renewable resources and others' main emergy data. Based on the respective transformity, the whole emergy can be calculated. According to Table 6, the sustainable indexes can be obtained in Table 7.

Table 2: Solar emergy calculation.

\begin{tabular}{|l|l|l|}
\hline 1 & Main area & $1100 \times 10^{6} \mathrm{~m}^{2}($ China Statistics Bureau Yearbook $)$ \\
\hline 2 & Insolation & $5.00 \times 10^{9} \sim 5.85 \times 10^{9} \mathrm{~J} / \mathrm{m}^{2} / \mathrm{yr}[12]$ \\
\hline 3 & Albedo & $0.30[13]$ \\
\hline 4 & Energy & $($ insolation $) \times(1$-albedo $) \times($ area $)=4.18 \times 10^{18} \mathrm{~J} / \mathrm{yr}$ \\
\hline 5 & UEV & $1.00 \mathrm{sej} / \mathrm{J}$ by definition \\
\hline 6 & Emergy & $4.18 \times 10^{18} \mathrm{sej}$ \\
\hline
\end{tabular}

Table 3: Wind emergy calculation.

\begin{tabular}{|l|l|l|}
\hline 1 & Main area & $1000000 \mathrm{~m}^{2}$ (China Statistics Bureau Yearbook) \\
\hline 2 & Air density & $1.29 \mathrm{~kg} / \mathrm{m}^{3}$ \\
\hline 3 & Velocity of geostrophic wind & $3.25 \mathrm{~m} / \mathrm{s}[14]$ \\
\hline 4 & Drag coefficient & $1.00 \times 10^{-3}[15]$ \\
\hline 5 & Energy & $\begin{array}{l}(\text { area }) \times(\text { air density) } \times(\text { drag coefficient }) \times \\
(\text { velocity of geostrophic wind })^{3}\end{array}$ \\
\hline 6 & UEV & $1500 \mathrm{sej} / \mathrm{J}$ \\
\hline 7 & Emergy & $7.88 \times 10^{15} \mathrm{sej}$ \\
\hline
\end{tabular}


Table 4: Rainwater emergy calculation.

\begin{tabular}{|l|l|l|}
\hline 1 & Main area & $600000 \mathrm{~m}^{2}($ China Statistics Bureau Yearbook $)$ \\
\hline 2 & Rainfall & $0.68 \mathrm{~m} /$ year[16] \\
\hline 3 & Average elevation & $316 \mathrm{~m}[17]$ \\
\hline 4 & Runoff rate & $40.00 \%$ \\
\hline 5 & Energy & $\begin{array}{l}(\text { area }) \times(\text { rainfall }) \times(\text { runoff rate }) \times(\text { water density }) \times \\
(\text { average elevation }) \times(\text { gravity })\end{array}$ \\
\hline 6 & UEV & $18000 \mathrm{sej} / \mathrm{J}[18]$ \\
\hline 7 & Emergy & $6.36 \times 10^{15} \mathrm{sej}$ \\
\hline
\end{tabular}

Table 5: Geothermal heat emergy calculation.

\begin{tabular}{|l|l|l|}
\hline 1 & Main area & $272 \times 10^{6} \mathrm{~m}^{2}($ China Statistics Bureau Yearbook $)$ \\
\hline 2 & Heat flow & $3.50 \times 10^{-2} \mathrm{~J} / \mathrm{m}^{2} / \mathrm{s}$ \\
\hline 3 & Energy & $($ area $) \times($ heat flow $)$ \\
\hline 4 & UEV & $34377 \mathrm{sej} / \mathrm{J}[18]$ \\
\hline 5 & Emergy & $3.27 \times 10^{11} \mathrm{sej}$ \\
\hline
\end{tabular}

Table 6: Emergy calculation of main energy and products in Yangzhou city.

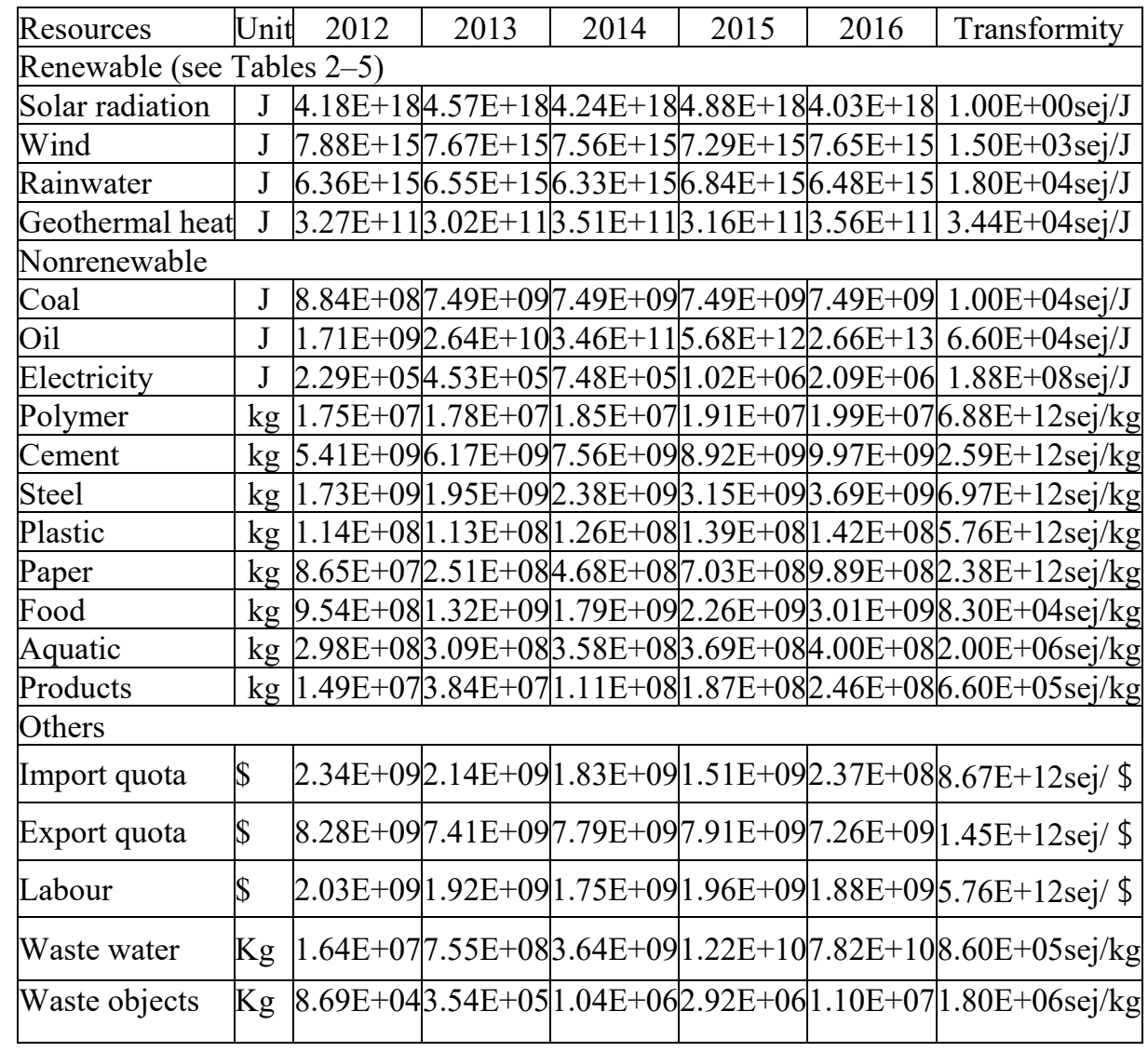


Table 7: The calculation results of sustainable indexes about Yangzhou city.

\begin{tabular}{|c|c|c|c|c|c|c|}
\hline Indexes & 2012 & 2013 & 2014 & 2015 & 2016 & Unit \\
\hline$R$ & $1.77 \mathrm{E}+20$ & $1.63 \mathrm{E}+20$ & $1.73 \mathrm{E}+20$ & $1.57 \mathrm{E}+20$ & $1.69 \mathrm{E}+20$ & sej \\
\hline$N$ & $1.18 \mathrm{E}+21$ & $1.34 \mathrm{E}+21$ & $1.56 \mathrm{E}+21$ & $2.03 \mathrm{E}+21$ & $2.41 \mathrm{E}+21$ & sej \\
\hline$Y$ & $1.36 \mathrm{E}+21$ & $1.51 \mathrm{E}+21$ & $1.72 \mathrm{E}+21$ & $2.18 \mathrm{E}+21$ & $2.58 \mathrm{E}+21$ & sej \\
\hline$F$ & $1.33 \mathrm{E}+21$ & $1.65 \mathrm{E}+21$ & $1.84 \mathrm{E}+21$ & $2.00 \mathrm{E}+21$ & $2.05 \mathrm{E}+21$ & sej \\
\hline Ep & $4.98 \mathrm{E}+14$ & $5.09 \mathrm{E}+14$ & $5.64 \mathrm{E}+14$ & $5.35 \mathrm{E}+14$ & $5.17 \mathrm{E}+14$ & sej/person \\
\hline Em & $7.53 \mathrm{E}+08$ & $8.01 \mathrm{E}+08$ & $8.36 \mathrm{E}+08$ & $8.49 \mathrm{E}+08$ & $8.89 \mathrm{E}+08$ & sej/capita \\
\hline Ec & $8.59 \mathrm{E}+10$ & $9.97 \mathrm{E}+10$ & $2.08 \mathrm{E}+11$ & $3.22 \mathrm{E}+11$ & $3.89 \mathrm{E}+11$ & sej/m ${ }^{2}$ \\
\hline ELR & 14.2 & 18.3 & 19.7 & 25.8 & 26.4 & none \\
\hline EYR & 1.02 & 0.91 & 0.93 & 0.92 & 1.26 & none \\
\hline ESI & 0.07 & 0.05 & 0.04 & 0.03 & 0.05 & none \\
\hline
\end{tabular}

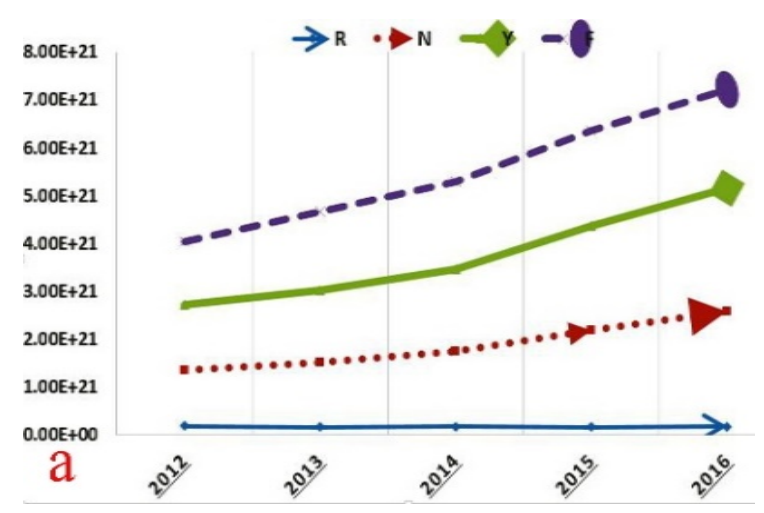

Figure 2: The main emergy evaluation indexes of Yangzhou city (a).

From Fig. 2, some trends of emergy indexes can be found. Renewable resources almost have no change from 2012 to 2016 . Non-renewable resources and import and export emergy have rapid growth.

Because the population and GDP are changing with emergy growth, Ep and Em have relatively stable changes. Due to stable area value of Yangzhou city, Ec has an obvious growth. The detail has been illustrated in Fig. 3.

As the most important indexes, ELR, EYR and ESI are shown in Fig. 4. Along with the development of Yangzhou city, Environmental loading ratio (ELR) increases year by year rapidly. The urban ecological sustainability has no improvement (see Fig. 4)

\subsection{GDP method to analyze the development of Yangzhou city}

Based on Table 8, the growth curve of GDP has been made from 2012 to 2016 and result is shown in Fig. 5.

Industry adjustment changes are shown in Fig. 6. Primary industry includes agriculture, forestry, fisheries, Animals husbandry. Secondary industry involves in mining industry, manufacturing, electric and gas industry, construction industry. Tertiary industry has financial industry, education and Culture, accommodation and catering and health services. 


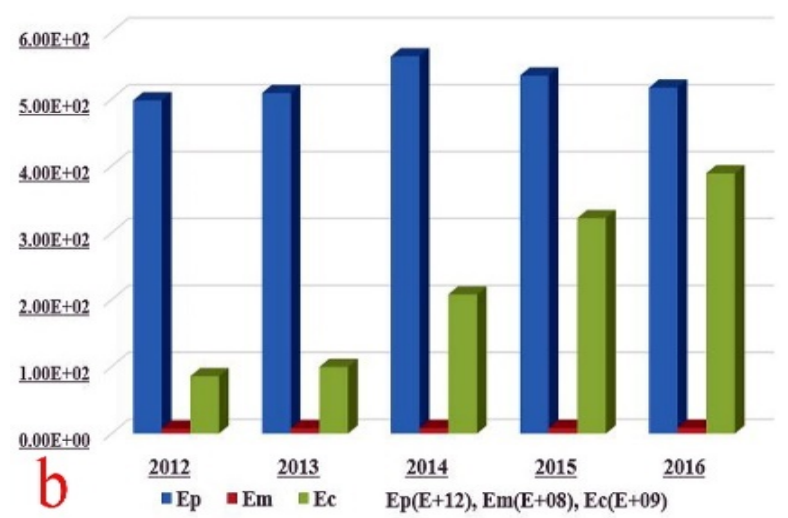

Figure 3: The main emergy evaluation indexes of Yangzhou city (b).

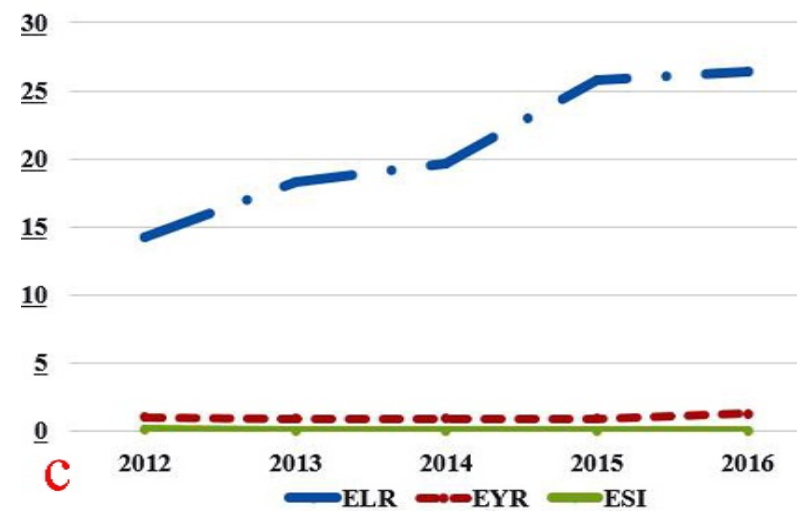

Figure 4: The main emergy evaluation indexes of Yangzhou city (c).

Table 8: Annual GDP of Yangzhou city from 2012 to 2016 (one hundred million $¥$ ).

\begin{tabular}{|c|c|c|c|c|c|c|c|}
\hline \multirow{2}{*}{ Year } & \multirow{2}{*}{ GDP } & $\begin{array}{c}\text { Primary } \\
\text { part }\end{array}$ & \multicolumn{3}{|c|}{ Secondary part } & \multirow{2}{*}{ Tertiary Part } & \multirow{2}{*}{ Per person } \\
\hline 2012 & 1949.19 & 73.17 & 944.57 & 124.53 & 1069.10 & 806.92 & 80824 \\
\hline 2013 & 2182.33 & 80.50 & 1025.21 & 133.51 & 1158.72 & 943.11 & 90352 \\
\hline 2014 & 2432.28 & 81.33 & 1106.27 & 140.10 & 1251.27 & 1099.68 & 100661 \\
\hline 2015 & 2639.82 & 87.67 & 1165.31 & 156.80 & 1321.89 & 1230.26 & 109000 \\
\hline 2016 & 2900.30 & 91.21 & 1262.33 & 158.60 & 1420.61 & 1388.48 & 119578 \\
\hline
\end{tabular}

Data references include: the website of Ministry of Environmental Protection of China; yearbook of Yangzhou City Bureau of Statistics; statistics Bureau of Jiangsu Province; China Statistics Bureau Yearbook. 


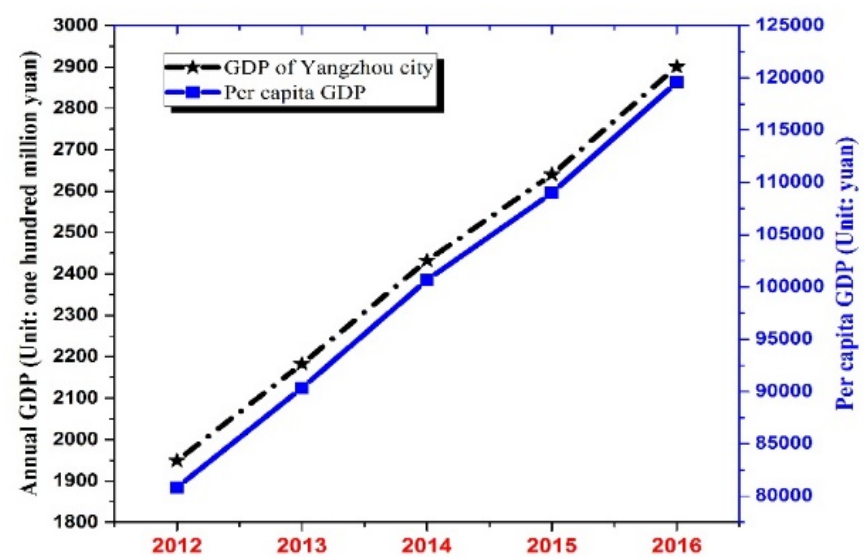

Figure 5: The GDP value of Yangzhou city.

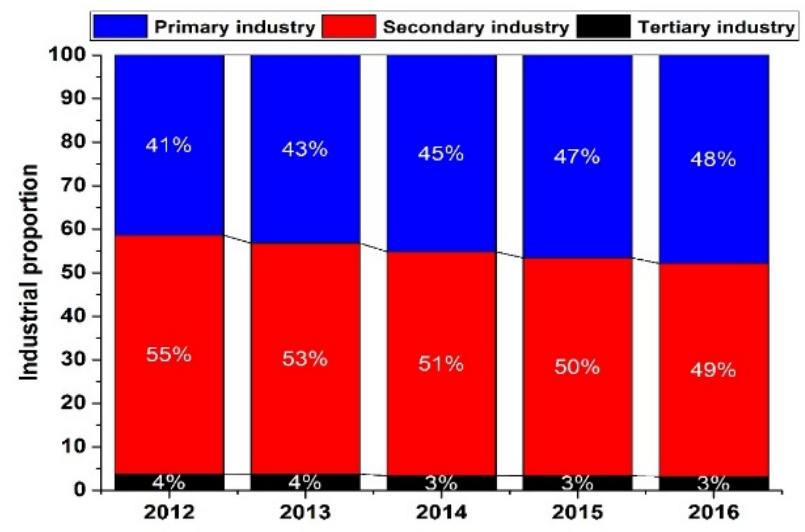

Figure 6: Industry adjustment changes.

From Figs 5 and 6, some results can be obtained. Yangzhou's GDP and per capita GDP grow rapidly from 2012 to 2016 . However, there is no satisfied effect about the goal of industry structural adjustment. The weights of secondary-industry have been reduced, but the tertiary-industry has not been promoted. On the contrary, the primary industry has a stable growth year by year.

\section{CONCLUSIONS}

According to the municipal government work report of Yangzhou city in 2012, the next 5 years' task is to adjust industry structure so as to keep a balance between the economy and city environment, especially to regulate ratio of primary, secondary and tertiary industry.

The ultimate goal is to increase the weight of tertiary industry and reduce primary and secondary industries from 2012 to 2016. 
Based on political policy impact, using emergy method and GDP method have assessed the ecological sustainability of Yangzhou city from 2012 to 2016.

The main results includes: 1. Renewable resources almost have no change from 2012 to 2016. Non-renewable resources and import and export emergy have rapid growth results. 2. Along with the development of Yangzhou city, Environmental loading ratio (ELR) increases year by year rapidly. The urban ecological sustainability has no improvement. 3. Yangzhou's GDP and per capita GDP grows rapidly from 2012 to 2016, however, there is no satisfied effect about the goal of industry structural adjustment.

In short, the development has not achieved the balance between economic development and ecological sustainability in Yangzhou city. The research significance of this article can optimize the government policy in order to have a better result.

\section{ACKNOWLEDGEMENT}

The work described in this paper was supported by the National Natural Science Foundation of China (51278107).

\section{REFERENCES}

[1] Shao, L. \& Chen, G.Q., Renewability assessment of a production system: Based on embodied energy as emergy. Renewable and Sustainable Energy Reviews, 57, pp. 380392, 2016. DOI: 10.1016/j.rser.2015.12.063.

[2] Zhang, Y., Yang, Z. \& Yu, X., Evaluation of urban metabolism based on emergysynthesis: A case study for Beijing (China). Ecological Modelling, 220(13-14), pp. 1690-1696, 2009. DOI: 10.1016/j.ecolmodel.2009.04.002.

[3] Mellino, S., Ripa, M., Zucaro, A. \& Ulgiati, S., An emergy-GIS approach to the evaluation of renewable resource flows: A case study of Campania Region, Italy, Ecological Modelling, 271, pp. 103-112, 2014.

DOI: $10.1016 /$ j.ecolmodel.2012.12.023.

[4] Huang, S.-L. \& Hsu, W.-L., 2003. Materials flow analysis and emergy evaluation of Taipeis urban construction. Landscape and Urban Planning, 63(2), pp. 61-74, 2003. DOI: 10.1016/s0169-2046(02)00152-4.

[5] Lei, K., Liu, L., Hu, D. \& Lou, I., Mass, energy, and emergy analysis of the metabolism of Macao. Journal of Cleaner Production, 114, 160-170, 2016.

DOI: $10.1016 /$ j.jclepro.2015.05.099.

[6] Lan, S.F \& Odum, H.T., Emergy evaluation of the environment and economy of Hong Kong. Journal of Environmental Sciences, 4, 432-439, 1994.

[7] Odum, H.T., Environmental Accounting: Emergy and Environmental Decision Making [M], John Wiley: New York, pp. 32-34, 1996.

[8] Brown, M.T. \& Ulgiati, S., Energy quality, emergy, and transformity: H.T.Odum's contributions to quantifying and understanding systems, Ecological Modelling, 178(12), pp. 201-213, 2004. DOI: 10.1016/j.ecolmodel.2004.03.002.

[9] Odum, H., Brown, M. \& Brandt-Williams, S., Handbook of Emergy Evaluation: a Compendium of Data for Emergy Computation in a Series of Folios, Folio. \# 1. Center for Environmental Policy, University of Florida: Gainesville, 2000.

[10] Brown, M.T. \& Herendeen, R.A., Embodied energy analysis and emergy synthesis: A comparative view. Ecological Economics, 19(3), pp. 219-235, 1996.

DOI: $10.1016 / \mathrm{s} 0921-8009(96) 00046-8$.

[11] Brown, M.T. \& Ulgiati, S., Emergy-based indices and ratios to evaluate sustainability: Monitoring economies and technology toward environmentally sound innovation. 
Ecological Engineering, 9(1-2), pp. 51-69, 1997.

DOI: 10.1016/s0925-8574(97)00033-5.

[12] Lu, Y.M., Yue, T.X., Chen, C.F., Fan, Z.M. \& Wang, Q.M., Solar radiation modeling based on stepwise regression analysis in China. Journal of Remote Sensing 14, pp. 852-864, 2010.

[13] Budikova, D. \& Hogan, C.M., 2010. Encyclopedia of earth. National Council for Science and the Environment. ed. J. Cutler, Online. www.eoearth.org/article/ Albedo?topic $=54300 \mathrm{~S}$. Accessed on: Apr. 2016.

[14] Reiter, E.R., 1969. Atmospheric Transport Processes, Part I. Energy Transfers and Transformations. AEC Critical Review Series. U.S. Atomic Energy Commission, Division of Technical Information, Oak Ridge, TN. p. 253.

[15] Miller, B.I., A study of the filling of hurricane Donna over land (2000). Monthly Weather Review. U.S. Department of Agriculture, 92, pp. 389-406, 1964.

[16] Gao, G., Chen, D.L., Xu, C.Y. \& Simelton, E., Trend of estimated actual evapotranspiration over China during 1960-2002. Journal of Geophysical Research, 112(D11), p. 120, 2007. DOI: 10.1029/2006jd008010.

[17] Wu, M.Q., Zhang, A.D., Kan, Z.Q., Sun, X.B. \& Lin, X., Land surface temperature retrieved using MODIS data in Shandong Province. 21 st International Conference on Geoinformatics, 2013.

[18] Brown, M.T. \& Bardi, E., Handbook of Emergy Evaluation: A Compendium of Data for Emergy Computation in a Series of Folios, Folio. \#3. Center for Environmental Policy, University of Florida, 2001. 